\title{
On the Realism of the Rain Microphysics Representation of a Squall Line in the WRF Model. Part II: Sensitivity Studies on the Rain Drop Size Distributions ${ }^{\mathscr{A}}$
}

\author{
CÉline Planche, ${ }^{\mathrm{a}}$ Frédéric Tridon,,${ }^{\mathrm{b}, \mathrm{e}}$ SANDrA BANSON, ${ }^{\mathrm{a}}$ Gregory THOMPSON, ${ }^{\mathrm{c}}$ \\ MARIE MONIER, ${ }^{\mathrm{a}}$ Alessandro BATTAGlia, ${ }^{\mathrm{d}}$ AND WOLFrAM WOBROCK ${ }^{\mathrm{a}}$ \\ ${ }^{a}$ Université Clermont Auvergne, INSU-CNRS UMR 6016, Laboratoire de Météorologie Physique, Clermont-Ferrand, France \\ ${ }^{\mathrm{b}}$ Earth Observation Science, Department of Physics and Astronomy, University of Leicester, Leicester, United Kingdom \\ ${ }^{\mathrm{c}}$ Research Applications Laboratory, National Center for Atmospheric Research, Boulder, Colorado \\ ${ }^{\mathrm{d}}$ Earth Observation Science, Department of Physics and Astronomy, and National Center for Earth Observation, \\ University of Leicester, Leicester, United Kingdom
}

(Manuscript received 19 January 2018, in final form 5 May 2019)

\begin{abstract}
A comparison between retrieved properties of the rain drop size distributions (DSDs) from multifrequency cloud radar observations and WRF Model results using either the Morrison or the Thompson bulk microphysics scheme is performed in order to evaluate the model's ability to predict the rain microphysics. This comparison reveals discrepancies in the vertical profile of the rain DSDs for the stratiform region of the squall-line system observed on 12 June 2011 over Oklahoma. Based on numerical sensitivity analyses, this study addresses the bias at the top of the rain layer and the vertical evolution of the DSD properties (i.e., of $D_{m}$ and $N_{0}^{*}$ ). In this way, the Thompson scheme is used to explore the sensitivity to the melting process. Moreover, using the Thompson and Morrison schemes, the sensitivity of the DSD vertical evolution to different breakup and self-collection parameterizations is studied. Results show that the DSDs are strongly dependent on the representation of the melting process in the Thompson scheme. In the Morrison scheme, the simulations with more efficient breakup reproduce the DSD properties with better fidelity. This study highlights how the inaccuracies in simulated $D_{m}$ and $N_{0}^{*}$ for both microphysics schemes can impact the evaporation rate, which is systematically underestimated in the model.
\end{abstract}

\section{Introduction}

Squall lines are mesoscale convective linear systems of organized deep convection that take place mostly in the tropics and midlatitudes. Squall-line strength and longevity depend on the balance between low-level wind shear and circulation associated with the storm-generated cold pool (Rotunno et al. 1998; Weisman and Rotunno 2004), the rear inflow jet characteristics, mid- and upperlevel shear, and characteristics of the presquall thermodynamic environment (e.g., the convective available

Supplemental information related to this paper is available at the Journals Online website: https://doi.org/10.1175/MWR-D-180019.s1.

\footnotetext{
${ }^{\mathrm{e}}$ Current affiliation: Institute for Geophysics and Meteorology, University of Cologne, Cologne, Germany.
}

Corresponding author: Céline Planche, celine.planche@uca.fr potential energy, the convective inhibition, and the level of free convection) (Evans and Doswall 2001). Although Parker and Johnson (2000) showed that $40 \%$ of these mesoscale convective linear systems studied in the central United States had parallel or leading stratiform regions, most of the mature squall lines had trailing stratiform regions. Some of the latter ones are characterized by three different regions: a leading line of convection with heavy precipitation, a well-defined transition zone with light precipitation and a trailing stratiform region with moderate precipitation. Squall-line systems have been widely studied (Houze 1977; Zipser 1977; Redelsperger and Lafore 1988; Biggerstaff and Houze 1993; Morrison et al. 2012; Wen et al. 2017; Fan et al. 2017; Fridlind et al. 2017) in order to understand the microphysics and dynamics interactions in the different regions.

Simulating squall lines with cloud-scale models remains a challenge due to the representation of the cloud microphysics. Ferrier et al. (1995) and Bryan and Morrison (2012) 
showed that rain evaporation has an important impact on the atmospheric buoyancy and subsequent cold pool evolution. In particular, differences in the rain drop size distribution (DSD) representation (van Weverberg et al. 2012) as well as the parameterization of the breakup process (Morrison and Milbrandt 2011; Morrison et al. 2012) lead to large differences in the evaporation rate and the resultant surface precipitation field.

Morrison et al. (2012) extended the work of Morrison and Milbrandt (2011) focusing on the sensitivity of a simulated squall line to raindrop breakup process in the Weather Research and Forecasting (WRF) Model simulations (Skamarock et al. 2008). In their work, the model results are compared to disdrometer measurements and radar retrievals based on polarimetric S-band radars of the U.S. NEXRAD network. The model produced too large median volume raindrop diameters $D_{0}$ while the bias in the reflectivity field was small [see Morrison et al. (2012) for more details]. Moreover, contrary to radar retrievals, the simulated raindrop median diameters were decreasing with height due to an excessive drop size sorting, which is a well-known issue for two-moment schemes (Wacker and Seifert 2001; Mansell 2010; Milbrandt and McTaggart-Cowan 2010). Indeed, thanks to comparisons with spectral microphysics scheme, Wacker and Seifert (2001) found too large rain sedimentation rates in simulations using bulk schemes. These unrealistic features in the vertical evolution of the rainwater content were described as mathematical artifacts due to the assumptions used in the bulk numerical approach.

The study of Gao et al. (2011) using a two-moment bulk microphysics scheme in the Chinese Academy of Meteorological sciences model found an improvement to rain DSD characteristics by increasing the efficiency of the breakup process. On the contrary, Morrison et al. (2012) showed that the use of several formulations for drop breakup failed to produce drop sizes and reflectivity simultaneously comparable to the observations, especially for all three areas of mature squall lines.

Moreover, the ice phase and its representation in mesoscale models directly influence the rain evolution and characteristics (Planche et al. 2015, among others). Using the WRF Model, Brown et al. (2017) showed that the rain resulting from the snow melting process in the Thompson scheme (Thompson et al. 2004, 2008), which is a partial two-moment scheme (one-moment representation for snow and two-moment representation for rain), had larger median raindrop sizes than polarimetric radar observations. Therefore, they altered the snow melting process [detailed in Brown et al. (2017)] in order to improve the comparisons between WRF and the observations of rain properties. These code modifications were tested for two hurricanes and the same idealized squall line that was used in Morrison et al. (2012).

Radar observations provide unique opportunities to test the ability of a model to reproduce the features of squall-line systems and provide observational constraints on the simulated rain DSDs. The assumed representation of the DSD is often in the form of the generalized gamma distribution (Verlinde et al. 1990); the shape parameter is typically set to zero, that leads to the simpler inverseexponential distribution. The assumed DSD has direct impacts onto the resulting rain process rates, such as evaporation, collection of other hydrometeors, terminal velocities, etc. As such, it is crucial to obtain detailed vertical and spatial observations of the rain DSD aloft.

Tridon et al. (2019, hereafter Part I) presented the rain DSD properties of the stratiform part of a squall line using a recently developed remote sensing technique applicable to measured cloud radar Doppler spectra at $\mathrm{K}_{a}$ and $\mathrm{W}$ band. It provides vertical profiles of DSDs at unprecedented spatial and temporal resolution (Tridon and Battaglia 2015; Tridon et al. 2017a,b). As such, the technique enables testing the realism of the DSD-derived parameters like concentration parameter $\left(N_{0}^{*}\right)$ [see Testud et al. (2001)] and mean volume diameter $\left(D_{m}\right)$ as they can be derived from the moments of the distribution. The comparison of retrieved DSD parameters to WRF Model simulations performed in Part I identified the inability of the model to reproduce the vertical variability of the DSD in the stratiform region of the squall-line system under study when using two commonly used WRF bulk microphysics schemes (i.e., Morrison and Thompson schemes).

In this Part II paper, we focus on the sensitivity of the microphysical processes relevant to rain drop size distributions in order to identify possible causes of the discrepancies between model and observations. The rain microphysics can be impacted by processes within the rain layer, in particular by the breakup and the selfcollection that influence the number and size of raindrops. Thus, the sensitivity of the vertical evolution of the DSDs for different parameterizations of breakup and self-collection is studied herein similar to the idealized framework of Morrison et al. (2012). Moreover, at the top of the rain layer, the DSDs are often greatly impacted by the assumed ice particle size distributions (PSDs) above the melting layer and/or by the melting representation itself. For example, Brown et al. (2017) made clear improvements to an earlier version of Thompson microphysics in regards to the number of rain produced by melting snow. Because of the importance of this process, we likewise include similar sensitivity experiments in this research. Until now, the accurate 
retrieval of ice PSD (or wetted ice PSD in the melting layer) from multifrequency radars is still a challenge; therefore, comparisons between modeled and observed ice PSD by radars are not addressed here. In the absence of a better alternative, a simple single frequency radar retrieval is used to evaluate if the bulk mass of ice is well reproduced by the model.

The paper is organized as follows: section 2 details the relevant aspects of the Thompson and Morrison bulk microphysics schemes with an emphasis on the rain representation and the microphysics processes pertinent in this study. Section 3 describes the comparison between the observed and the simulated DSDs using the reference version of the two microphysics schemes (named CTL simulations in Part I). Section 4 presents the sensitivity of the DSD parameters to the parameterization of raindrop breakup and self-collection as well as the snow melting process, and the impact of the rain size sorting. Section 5 estimates the impact of the inaccuracy in the modeled DSDs on the evaporation process that elucidates remaining problems. Section 6 summarizes the main findings of this analysis.

\section{Simulation setup}

\section{a. Case specification}

The squall line under study was observed on 12 June 2011 over Oklahoma by S-band radars from the U.S. NEXRAD network and measurements from the Southern Great Plains (SGP) Central Facility of the U.S. Department of Energy Atmospheric Radiation Measurement (ARM) program. The synoptic conditions responsible for the formation of this system and its evolution were provided in Part I.

To evaluate the representation of the rain processes of the squall line in WRF, the retrievals from multifrequency cloud radar Doppler spectra observations described in Part I are compared to WRF v3.6.1 model (Skamarock et al. 2008). The model configuration used in this study is described in Part I. This study focuses on the vertical evolution of the DSD parameters (i.e., $D_{m}$ and $N_{0}^{*}$ ). Part I provides a comparative analysis between available observations (e.g., the $3 \mathrm{D}$ wind and the relative humidity) and simulations using either the Morrison scheme or the Thompson scheme. The model reasonably reproduces the overall features of the studied squall line (e.g., the timing and the spatial evolution), but has few difficulties to reproduce specific features such as the intensity of the wind shear ahead of the system at the SGP location, the relative humidity in the stratiform period and the characteristics of the transition zone using either microphysics scheme. Since a model cannot be expected to reproduce observations at one location, a statistical approach is used to compare the microphysics properties in the following sensitivity studies. Nevertheless, the statistical approach cannot alleviate the fact that the vertical profiles at the SGP site may not be representative of the whole system.

\section{b. Details about the microphysics schemes}

Within the model configuration described in Part I, two bulk microphysical parameterizations are tested: the partial double-moment scheme described by Thompson et al. $(2004,2008)$ and the double-moment scheme described by Morrison et al. (2009). The Thompson scheme predicts both the number concentration and the mixing ratio of rain and cloud ice, but only the mixing ratio for cloud water, graupel, and snow. The Morrison doublemoment scheme predicts mixing ratio and number concentration for all hydrometeors species, except cloud water. The results from simulations using the Morrison scheme presented hereafter are obtained using hail as rimed ice species with a density of $900 \mathrm{~kg} \mathrm{~m}^{-3}$ and associated fall speed parameters according to Matson and Huggins (1980). Note that simulations using graupel instead of hail as rimed ice species were also performed and provided similar conclusions (not shown). While each species is described in more detail in the references above, we specifically detail the rain representation as well as the processes that are pertinent to this study (i.e., the raindrop breakup and the snow melting processes).

The Thompson as well as the Morrison schemes assume that the rain DSD, $N(D)$, follows a generalized gamma function (Verlinde et al. 1990; Walko et al. 1995):

$$
N(D)=N_{0} D^{\mu} e^{-\lambda D},
$$

where $N_{0}, \lambda$, and $\mu$ are, respectively, the intercept, the slope, and the shape parameters of the size distribution, and $D$ is the diameter. With both schemes using two moments for describing the rain species, $N_{0}$ and $\lambda$ are two free parameters determined from the predicted rain mass mixing ratio $q_{r}$ and raindrop number concentration $N_{r}$ :

$$
\begin{aligned}
N_{0} & =\frac{N_{r} \lambda^{\mu+1}}{\Gamma(\mu+1)}, \\
\lambda & =\left[\frac{a N_{r} \Gamma(\mu+1+b)}{q_{r} \Gamma(\mu+1)}\right]^{1 / b} .
\end{aligned}
$$

The values for $a$ and $b$ are given by an assumed powerlaw mass-diameter relationship $m(D)=a D^{b}$ for the precipitating hydrometeors (Thompson et al. 2008; Morrison et al. 2009). In Morrison and Thompson $\mu$ is 
assumed equal to 0 for rain species so that the rain distribution [Eq. (1)] fits the classic exponential distribution and $N_{0}$ becomes the physical intercept of this distribution (Marshall and Palmer 1948). Note that $\mu$ can also impact the rain microphysics processes but such analysis is out of the scope of this work.

Empirical laws are used to describe the terminal velocity $V(D)$ as a function of particle diameter for each species. For raindrops, Morrison et al. (2009) used a power-law relationship whereas Thompson et al. (2008) used a relationship based on Ferrier (1994). This latter relationship includes an exponential term $V(D)=\alpha D^{\beta} e^{-\gamma D}$, where $\alpha$, $\beta$, and $\gamma$ are constant. Nissan and Toumi (2013) showed that this representation is able to reproduce the plateau of fall speed as drop size increases [as described in Atlas et al. (1973)] whereas the power-law formulations (Liu and Orville 1969; Atlas and Ulbrich 1977) lead to a large overestimation of fall speed for larger drops. The Morrison scheme limits this pitfall through a maximum raindrop fall velocity limit of $9 \mathrm{~m} \mathrm{~s}^{-1}$ at standard temperature and pressure.

In both Morrison and Thompson schemes, the parameterization of rain breakup and rain self-collection follows a modified version of the Verlinde and Cotton (1993) parameterization. More specifically, the raindrops number concentration tendency $d N_{r}$ during self-collection and breakup is governed by

$$
d N_{r}=\alpha_{\mathrm{nr}} E_{c} N_{r} \mathrm{LWC},
$$

where $\alpha_{\mathrm{nr}}$ is a weighting factor, $E_{c}$ is a bulk collection efficiency, $N_{r}$ is the existing rain number concentration, and LWC is the liquid water content of the rain species. Differences between the original Verlinde and Cotton (1993), Morrison, and Thompson implementations are found in the weighting factor and the collection efficiency. Figure 1 presents the evolution of $E_{c}$ in the Morrison scheme as a function of the mean drop size and shows that $E_{c}$ decreases to a negative number as the mean size increases, which corresponds to drop breakup.

In either Morrison or Thompson scheme, the efficiency parameter $E_{c}$ is given by

$$
\begin{aligned}
& E_{c}=1, D_{r}<D_{\text {th }}, \\
& E_{c}=2-\exp \left[2300\left(D_{r}-D_{\text {th }}\right)\right], \quad D_{r} \geq D_{\text {th }},
\end{aligned}
$$

where $D_{\text {th }}$ is a threshold diameter at which the collection efficiency begins to decrease. $D_{\text {th }}$ depends on the mean number-weighted raindrop diameter [definition in Straka (2009)] for the Morrison scheme and on the median volume diameter for the Thompson scheme. Indeed, $D_{\text {th }}=300 \mu \mathrm{m}$ for the Morrison control simulations

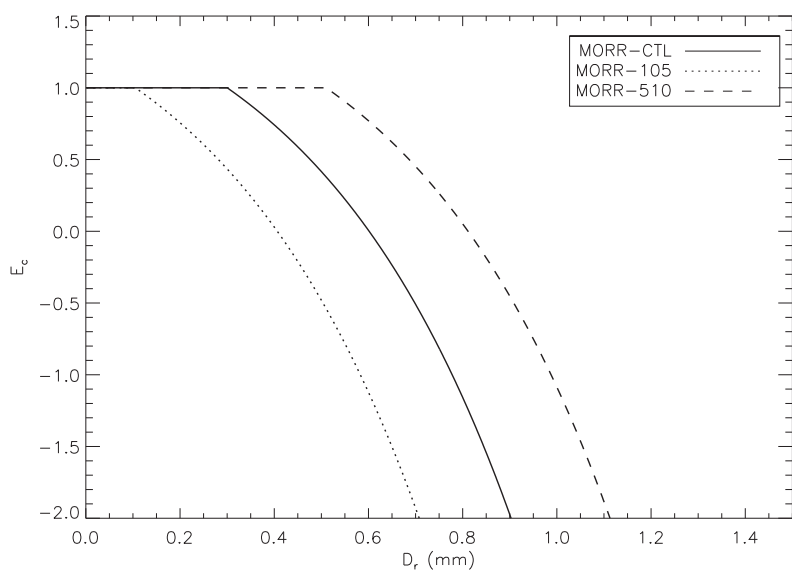

FIG. 1. Rain self-collection efficiency $E_{c}$ as a function of mean drop size $D_{r}$ for various thresholds $D_{\text {th }}$ at which breakup process occurs. Adapted from Morrison et al. (2012).

(MORR-CTL) whereas for the Thompson scheme the median volume diameter threshold is set to $1.6 \mathrm{~mm}$. In addition, the Thompson scheme uses $\alpha_{\mathrm{nr}}=0.5$ while the Morrison scheme uses a value of unity. To investigate the sensitivity to the efficiency of drop breakup process and its impact on the rain DSD evolution, two simulations were performed using the same methodology as in Morrison et al. (2012) decreasing $D_{\text {th }}$ to $105 \mu \mathrm{m}$ or increasing $D_{\text {th }}$ to $510 \mu \mathrm{m}$ (simulations called MORR105 and MORR-510, respectively). As shown in Fig. 1 (and Table 1), the MORR-105 case gives more efficient breakup whereas MORR-510 produces less efficient breakup as compared to the MORR-CTL case.

Moreover, the DSD characteristics below the melting layer in the Thompson scheme are sensitive to the snow melting representation, since a one-moment snow species becomes a two-moment rain species. In the Thompson scheme, the production of raindrops from melting snow is given by

$$
\frac{d N_{r}}{d t}=\frac{M_{0} 10^{m T_{c}}}{q_{s} \rho}\left(\frac{d q_{r}}{d t}\right)
$$

where $N_{r}, q_{r}$, and $q_{s}$ are, respectively, the concentration of raindrops and the mixing ratios of rain and snow, $T_{c}$ is the temperature $\left({ }^{\circ} \mathrm{C}\right), \rho$ is the density of moist air, and $M_{0}$ is the zeroth moment (i.e., number concentration) of the particle size distribution for snow. The form of the Eq. (7) is nearly identical to the Morrison scheme except that the numerator term on the right-hand side is replaced by the snow number concentration, which is a predicted variable in the Morrison scheme. The sole purpose of the constant, $m$, in Eq. (7) is to account for the fact that the smallest snow particles are the quickest to melt. Thompson et al. (2008) had set this constant 
TABLE 1. Description of the microphysical parameterization modification experiments using either the Thompson (THOM) or Morrison (MORR) scheme.

\begin{tabular}{|c|c|}
\hline Name & Description \\
\hline THOM-CTL & $\begin{array}{l}\text { Modified Verlinde and Cotton (1993) breakup } \\
\text { parameterization with } D_{0, \text { th }}=1.6 \mathrm{~mm} \text { and } \\
\alpha_{\mathrm{nr}}=0.5 \text { (original v3.6.1 configuration) }\end{array}$ \\
\hline THOM-N25 & $\begin{array}{l}\text { As in THOM-CTL, but with snowmelt } \\
\text { exponential constant } m \text { set to }-0.25 \text { and no "if" } \\
\text { statement on } q_{s} \text { and } T_{c} \text { [as in Brown et al. (2017)] }\end{array}$ \\
\hline THOM-BKP & $\begin{array}{l}\text { As in THOM-N25, but with } D_{0, \text { th }}=1.95 \mathrm{~mm} \\
\text { and } \alpha_{\mathrm{nr}}=2.0\end{array}$ \\
\hline MORR-CTL & $\begin{array}{l}\text { Modified Verlinde and Cotton (1993) breakup } \\
\text { parameterization with } D_{\text {th }}=300 \mu \mathrm{m} \\
\text { (original v3.6.1 configuration) }\end{array}$ \\
\hline MORR-510 & $\begin{array}{l}\text { As in MORR-CTL, but with } D_{\text {th }}=510 \mu \mathrm{m} \text { (i.e., } \\
\text { less efficient breakup) }\end{array}$ \\
\hline MORR-105 & $\begin{array}{l}\text { As in MORR-CTL, but with } D_{\text {th }}=105 \mu \mathrm{m} \text { (i.e., } \\
\text { more efficient breakup) }\end{array}$ \\
\hline MORR-SS & $\begin{array}{l}\text { As in MORR-CTL, but removing the size } \\
\text { sorting of raindrops }\end{array}$ \\
\hline MORR-510-SS & $\begin{array}{l}\text { As in MORR-510, but removing the size sorting } \\
\text { of raindrops }\end{array}$ \\
\hline MORR-105-SS & $\begin{array}{l}\text { As in MORR-105, but removing the size sorting } \\
\text { of raindrops }\end{array}$ \\
\hline
\end{tabular}

equal to -0.75 in order to obtain a constant vertical profile of radar reflectivity below the melting layer. Two additional constraints were imposed with no production of raindrops from melting snow when $q_{s}<0.005 \mathrm{~g} \mathrm{~kg}^{-1}$ or when $T_{c}>3.5^{\circ} \mathrm{C}$. Simulations with this original version of the Thompson scheme will be referred to as THOM-CTL. Brown et al. (2017) modified the original Thompson scheme removing the two additional constraints (on $q_{s}$ and $T_{c}$ ) and changing the value of $m$ to be -0.25 . These simulations will be referred to as THOM-N25. The simulation for which the values related to Eq. (4) are changed is referred to as THOM-BKP. All experiments are summarized in the Table 1.

The two bulk schemes use different approaches to limit the possibility of excessive size sorting during sedimentation. In Thompson scheme, there is an absolute limit of $2.5 \mathrm{~mm}$ median volume diameter $D_{0}$ (which is close to the mean volume diameter when $\mu=0$, see Part I) such that if $D_{0}>2.5 \mathrm{~mm}$, then the number of drops is increased to balance back to that maximum $D_{0}$. In the Morrison scheme, a limit on $\lambda$ is imposed primarily to avoid inconsistencies between prognostic mass and number concentration that can arise, for example, from advection (H. Morrison 2018, personal communication). However, this limit $\left(\lambda\right.$ is required to be larger than $357 \mathrm{~m}^{-1}$, which corresponds to a limit of $10.3 \mathrm{~mm}$ on $D_{0}$, since $D_{0}=$ $(3.67+\mu) / \lambda)$ will not play a significant role because the breakup parameterization in the Morrison scheme will prevent the mean drop size from attaining such large values.

\section{DSD evolution in CTL simulations}

Figure 2a shows the temporal evolution of the vertical profile of the reflectivity measured by the UHF wind profiler radar, reconfigured in precipitation mode (Tridon et al. 2013), located at the ARM SGP site. It presents the common morphological features of a squall-line system that comprises a convective region (CR) with heavy precipitation and deep cloud height, a transition zone (TZ) of light precipitation followed by a stratiform region (SR) with moderate precipitation. The rain characteristics of the regions of the squall line are known to be significantly different and an objective distinction of the CR, $\mathrm{TZ}$ and SR is required for the model-observations comparisons [as in Jensen et al. (2018)]. The detection of the different regions is based on the features in the reflectivity fields $(Z)$ measured by the UHF wind profiler radar and on the evolution of the rain rate $(R)$ obtained from the multifrequency cloud radar retrieval (described in Part I) in the middle of the rain layer (i.e., at 2-km height):

- the CR is marked by a contiguous zone where $R>$ $20 \mathrm{~mm} \mathrm{~h}^{-1}$

- the SR is defined by a subsequent contiguous zone where $Z>30 \mathrm{~dB} Z$ and with an absolute value of vertical wind within the whole column lower than $5 \mathrm{~m} \mathrm{~s}^{-1}$, and

- the TZ is found if there is a reflectivity minimum between the CR and SR, which is at least $3 \mathrm{~dB}$ lower than the mean $Z_{\mathrm{SR}}$.

The threshold set for the definition of the SR may appear to be relatively high but it matches the observations, where $Z_{\mathrm{SR}}$ within the rain layer is consistently composed between 35 and $40 \mathrm{~dB} Z$ (corresponding to moderate rain rate) and followed by the sudden decay of precipitation. Thus, it restricts model-observations comparisons to similar rain regimes.

Figure 4 of Part I showed that the temporal and spatial features of the squall line were well simulated by MORR-CTL and THOM-CTL, although the system was predicted a bit too far to the north. To improve the robustness of our model-observations comparisons, a statistical analysis similar to Varble et al. (2014) is performed on multiple time-height cross sections derived at several locations along the simulated squall-line system. Examples of the radar reflectivity fields simulated in THOM-CTL and MORR-CTL are shown in Figs. $2 b$ and $2 \mathrm{c}$ and in Figs. S1 and S2 of the supplemental material of Part I. According to these vertical cross sections, the typical characteristics of the squall line for the leading convective line and the trailing stratiform region are quite well reproduced. However, both simulations 

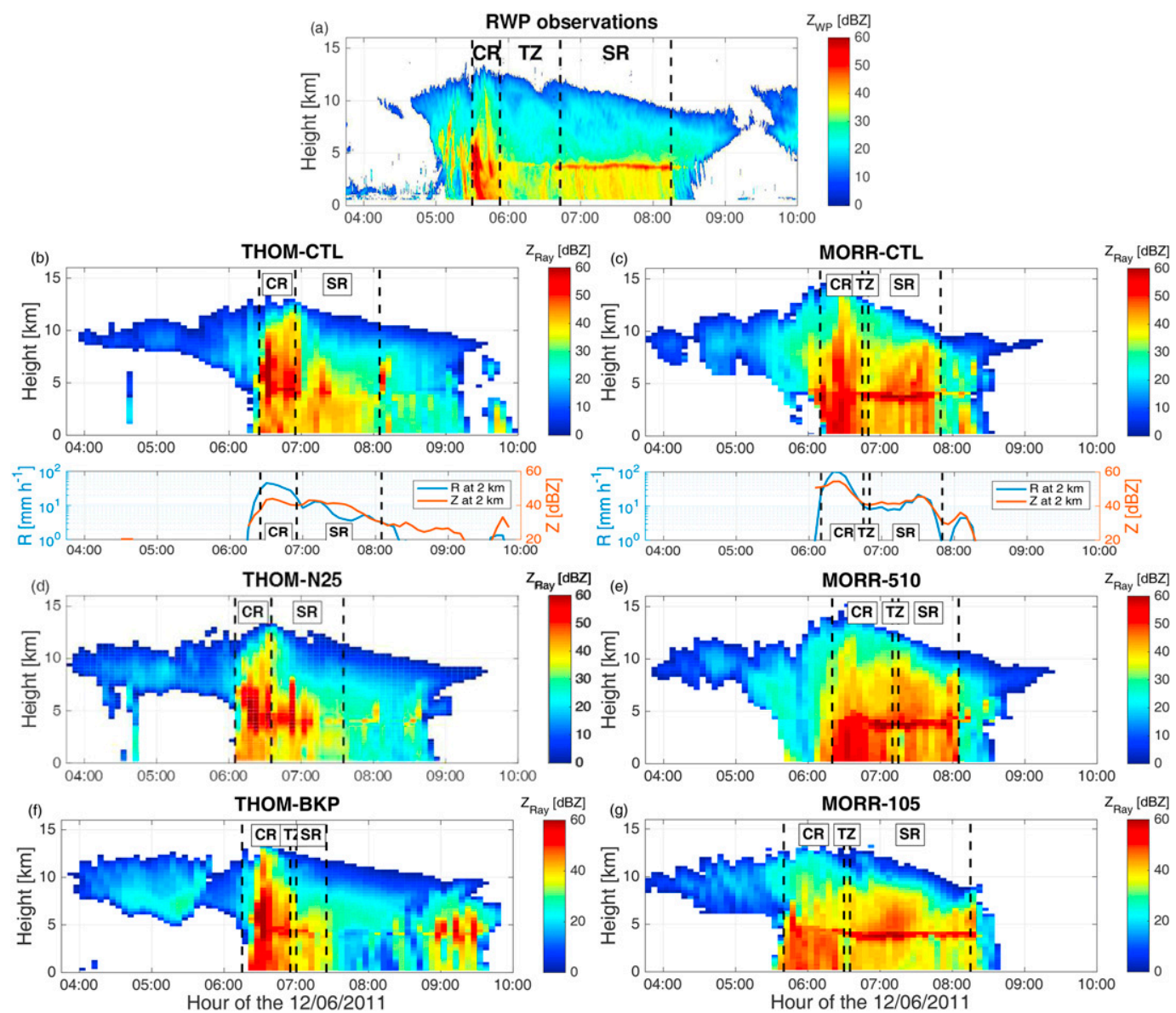

FIG. 2. Comparison of the temporal evolution of the reflectivity profile (a) measured by the UHF Radar Wind Profiler (RWP) located at the Southern Great Plains ARM facility on 12 Jun 2011 and (b)-(g) obtained by simulations at the same location using the different microphysical parameterization modification experiments described in Table 1. Additional time-height cross sections derived at several locations along the simulated squall-line system are available in the supplemental material. CR, TZ, and SR correspond to the convective region, the transition zone, and the stratiform region of the squall line. The temporal evolution of the parameters used in the automatic detection of these regions (i.e., $Z$ and $R$ at 2-km height) is represented for (b) THOM-CTL and (c) MORR-CTL.

struggle to reproduce the $\mathrm{TZ}$, which is basically missing in THOM-CTL and whose duration is too short in MORR-CTL. While idealized studies showed that it is possible to reproduce the TZ (e.g., Morrison et al. (2012); Jensen et al. (2018)), the difficulty in reproducing this specific region was already highlighted in previous real case studies (e.g., in Fan et al. 2017).

Consistent with Part I, we decided to study the DSD properties using the same retrieved parameters $N_{0}^{*}$ and $D_{m}$ [for definition, see Eqs. (1) and (2) in Part I] rather than the raindrop number concentration $N_{r}$ used in many modeling studies. Note that as $\mu$ equals 0 in both microphysics schemes, $N_{0}^{*}$ is defined as $N_{0}^{*}=4 N_{r} / D_{m}$. For an easier interpretation of the vertical evolution of the DSDs, $N_{0}^{*}$ and $D_{m}$ are averaged over the periods of the squall line as defined in Fig. 2 and for the multiple model cross sections.

Since the retrieved profiles in the CR are capped at low levels due to the full extinction of the radar signal (see Fig. 8 in Part I) and the model struggles to reproduce the TZ, only the rain microphysics results for the SR of the squall line are analyzed below. Looking at the dual-frequency retrieval (black lines and gray shading in Figs. 3 and 4), the mean volume diameter $D_{m}$ increases toward the ground for the SR period from 1.8 to $2 \mathrm{~mm}$, while $N_{0}^{*}$ decreases. Figures 3 and 4 also present the median vertical profiles of the DSD parameters obtained from the CTL simulations (blue lines).

As in Morrison et al. (2012), the MORR-CTL simulation shows an excessive increase of $D_{m}$ toward the ground compared to observations (Fig. 3a). This is 

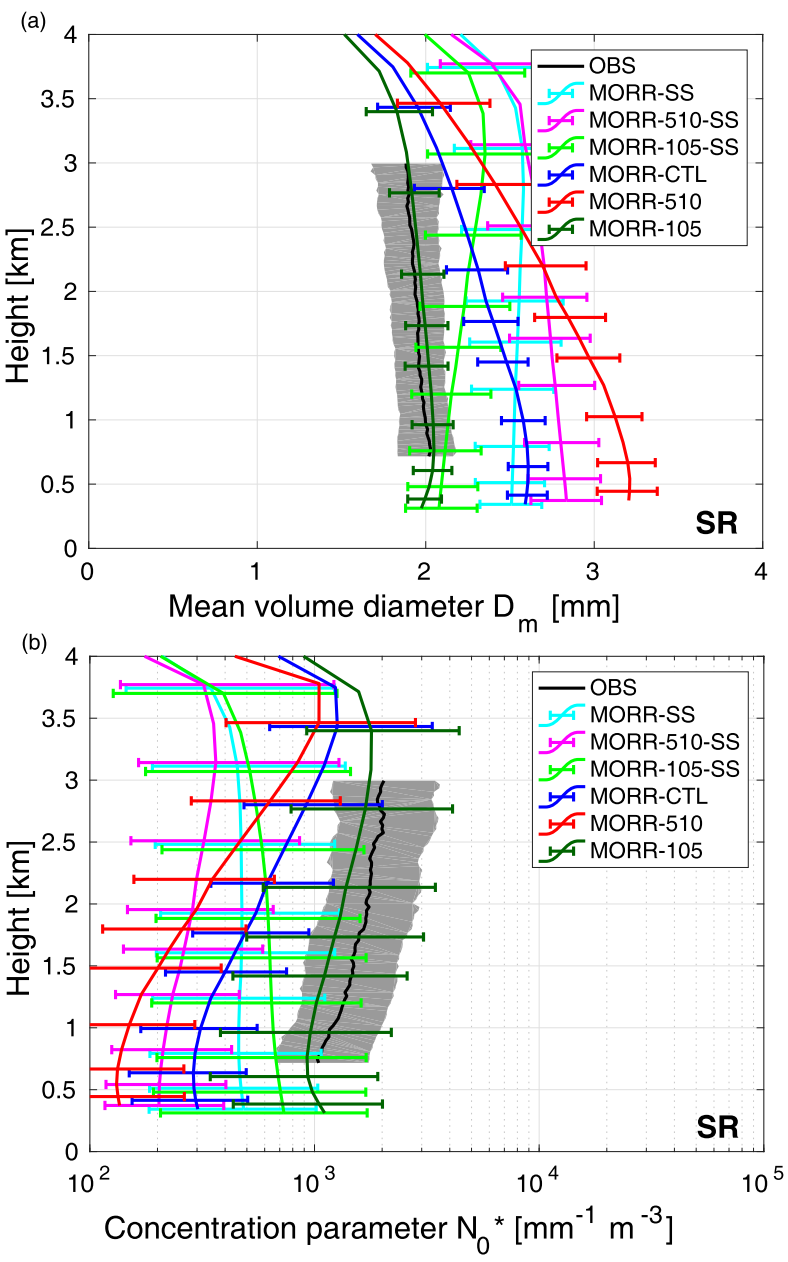

FIG. 3. Median vertical profiles of the (a) mean volume diameter $D_{m}$ and (b) the concentration parameter $N_{0}^{*}$ during the stratiform region (SR) retrieved from observations and in MORR-CTL, MORR-510, and MORR-105 simulations, and in the respective simulations controlling the size sorting of raindrops (i.e., MORRSS, MORR-510-SS, and MORR-105-SS). The median profiles are given with the first and third quartiles that are computed using all values accumulated from the entire ensemble of time-height locations. The average is done using the different model time-height sections defined in section 3 .

associated with a sharp decrease of $N_{0}^{*}$ (Fig. 3b). As was shown by Barthes and Mallet (2013) using detailed simulations of the DSD evolution for similar rain rates, such an increase is not realistic: $D_{m}$ should not increase by more than $0.5 \mathrm{~mm}$ in $3 \mathrm{~km}$. Note that the observed profiles of the DSD parameters are quite consistent within the SR of the squall-line system. As proposed by Morrison et al. (2012), this atypical vertical variation may be connected to the excessive drop size sorting during sedimentation; this issue is particularly acute in the majority of two-moments schemes (Wacker and Seifert 2001; Milbrandt and McTaggart-Cowan 2010). At this stage, it is difficult to assess whether this vertical
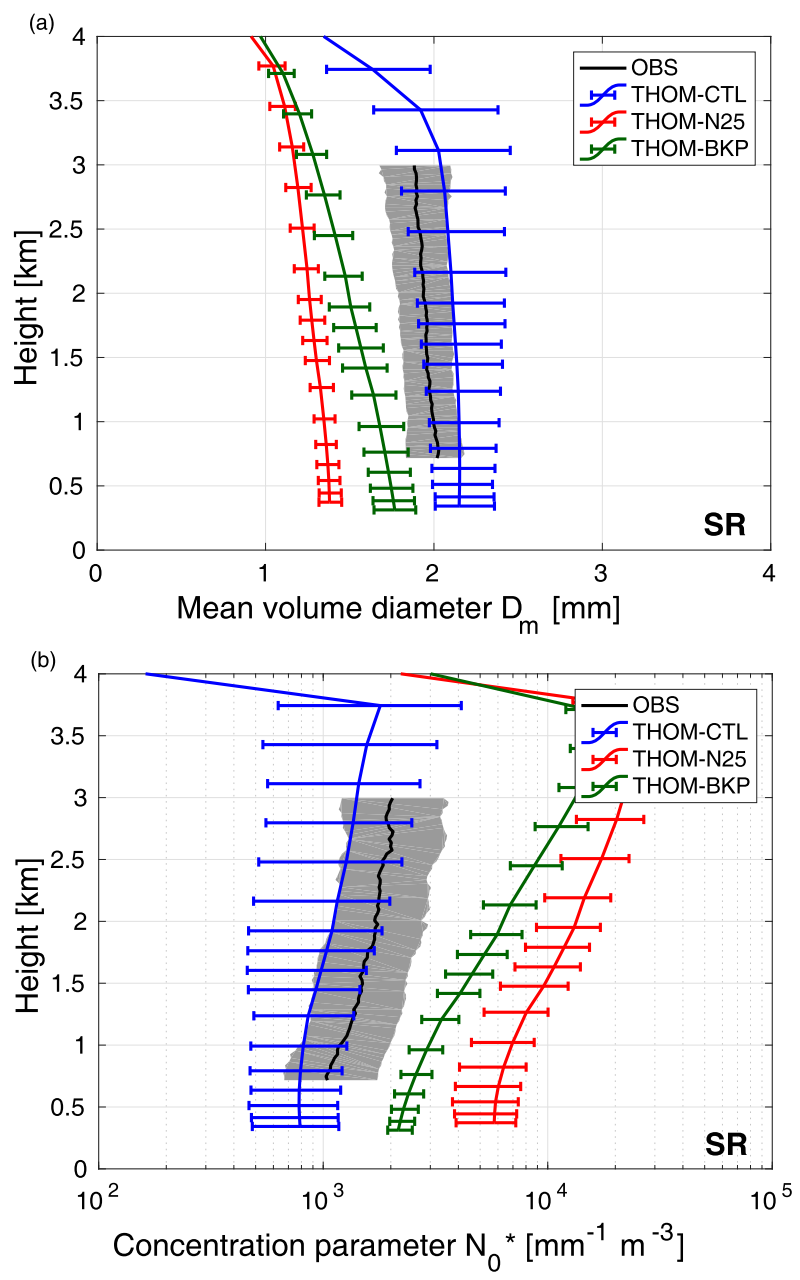

FIG. 4. As in Fig. 3, but for THOM-CTL, THOM-N25, and THOM-BKP simulations.

variation is caused by the parameterization of raindrop breakup and self-collection or by the excessive size sorting solely. This is an important issue to resolve as, in a subsaturated environment, as in this case (see section 5), such an incorrect representation of the DSD profile can lead to inaccurate evaporation rates. Indeed, under evaporation, the diameter of smaller drops decreases more rapidly than larger drops, which leads to a slight increase of $D_{m}$ toward the ground (Kumjian and Ryzhkov 2010). As a consequence, larger evaporation in MORR-CTL could also explain the excessive gradient in $D_{m}$ profile compared to the observations. However, this is not compatible with a relative humidity $(\mathrm{RH})$ larger in MORR-CTL than in the observations (as shown in Part I).

The disagreement at the top of the rain layer suggests that the ice phase could also partly impact the properties of $D_{m}$ and $N_{0}^{*}$ within the rain layer. Figure 5 shows the mean profile of the ice mixing ratio retrieved from the wind profiler reflectivity thanks to the empirical relation 

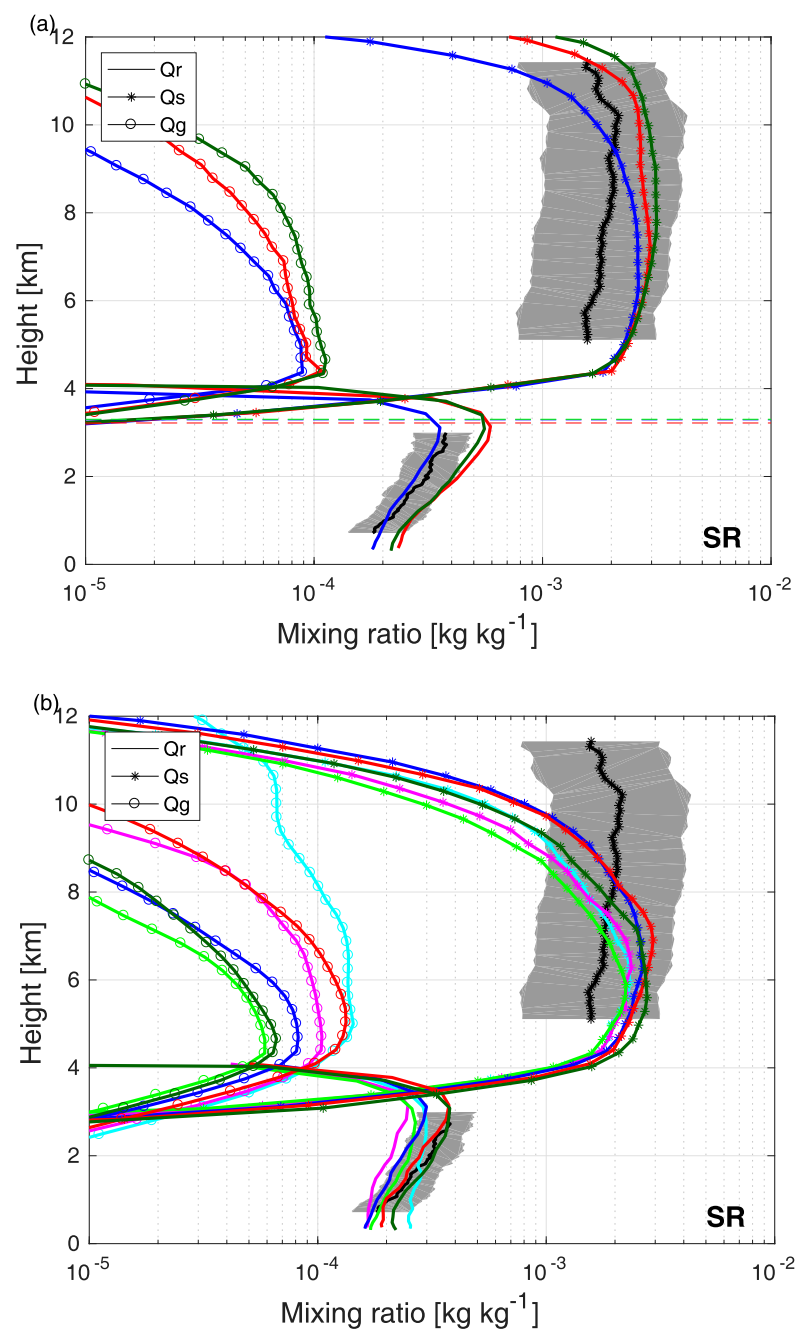

FIG. 5. Median vertical profile of the mixing ratios of snow, graupel, and rain during the stratiform region (SR) obtained with the retrieved observations (black) and for the different simulations using (a) the Thompson scheme or (b) the Morrison scheme. The colors are the same as the ones used in Figs. 3 and 4. The horizontal dashed lines represent the altitude of the $3.5^{\circ} \mathrm{C}$ isotherm for each of the tests performed with the Thompson scheme. The median is done using the different model time-height sections defined in section 3. No retrievals are made in the layer where melted hydrometeors are present.

proposed by Hogan et al. (2006). Note that the uncertainty of such a simple retrieval (developed for lower $Z$ ) is high and could explain the unexpected decrease of the retrieved IWC toward the ground for the SR portion of this squall-line system. Figure 5 shows that the simulated mean vertical profile of ice (i.e., snow plus graupel) mixing ratio in MORR-CTL is included within the range of observations from 5- to $10-\mathrm{km}$ height. However, since the retrieval of $D_{m}$ and $N_{0}^{*}$ in the ice phase remains challenging, we cannot compare the simulated ice PSDs to the observations. Thus, we have to keep in mind that the ice PSD differences are unknown and could play an important role in the DSD evolution.

While it also uses a two-moment representation for rain, the THOM-CTL simulation seems to be less affected by an excessive size sorting; $D_{m}$ and $N_{0}^{*}$ have a much weaker variation in the vertical. This can be due to the fact that, in addition to the mean volume diameter limit defined in section $2 b$, the number-weighted mean rain fall speed is forced to be close to the mass-weighted mean fall speed by artificially using a different value of the shape parameter (i.e., $\mu=1.5$ only in the computation of the number-weighted fall speed). The overall profiles of $D_{m}$ and $N_{0}^{*}$ are matching the observations. Moreover, the rain mixing ratio $\left(q_{r}\right)$ is well estimated within the rain layer (Fig. 5a). However, while the median profiles of the DSD parameters are close to the observations, the spread of the values (Fig. 4) for $N_{0}^{*}$ are much larger, implying an unrealistic variation of this parameter that is not visible in the observations. Furthermore, as shown in Fig. 18 in Part I, the narrow spread of the $D_{m}$ values above and below the median underpins an unrealistic large number of occurrences where the median volume diameter $D_{0}$ reaches the absolute limit of $2.5 \mathrm{~mm}$ defined in section $2 \mathrm{~b}$. As this occurs predominantly at the top of the rain layer, one question naturally arises and will be addressed in the next section: can the DSD properties at the top of the layer be improved with a modified melting scheme?

\section{Sensitivity of DSD to parameterizations of microphysics processes}

\section{a. Thompson scheme}

To obtain DSD parameters in better agreement with the observations below the melting layer, we test in THOM-N25 the sensitivity of the DSDs to assumptions used in the snow melting parameterization. In THOM$\mathrm{N} 25$, the snow melting process follows the recent modifications of the Thompson scheme made by Brown et al. (2017). These alterations with respect to THOM-CTL are summarized in section $2 \mathrm{~b}$ and Table 1 .

The temporal evolution of the radar reflectivity field over the SGP site and at several locations through the simulated squall-line system reveals that the timing and intensity in the SR are reasonably reproduced in THOM-N25 as it was before in THOM-CTL (Figs. 2b,d). The strength of the CR becomes weaker compared to THOM-CTL, but still overestimates the radar observations (see also Fig. S2 of the online supplemental material). Also this model configuration does not reproduce the $\mathrm{TZ}$ and this is true for the majority of the model cross sections. Moreover, in both simulations (see Figs. S1 and S2 of, respectively, the supplemental material of Part I 
and II), the bright band is thinner than observed (Fig. 2a). Since the model does not explicitly simulate the melted hydrometeor properties, major assumptions are made to calculate the effects of these wetted ice particles on the radar reflectivity field (Blahak 2007). No further comparisons between observations and simulations will be done regarding the bright band.

Figure $4 \mathrm{~b}$ confirms that the increase of the constant exponent $m$ in the Eq. (7) from -0.75 to -0.25 causes an increase in the production of raindrops from the melted snow. Indeed, the concentration parameter $N_{0}^{*}$ is much greater in THOM-N25 than in THOM-CTL along the whole profile for the SR. This increase in the raindrop number induces a decrease of the mean volume diameter (Fig. 4a).

It appears that the changes in the DSD profile induced by the modification of the melting scheme clearly increase the differences between observations and simulations. The mean volume diameter $D_{m}$ is underestimated by almost a factor of 1.5 through the rain layer. Just below the melting layer, the simulated concentration parameter $N_{0}^{*}$ is overestimated by more than one order of magnitude. Despite a stronger decrease of $N_{0}^{*}$ toward the ground, it remains much larger than in the observations and in MORR-CTL. These results suggest that the changes made in THOM-N25 (described in section $2 \mathrm{~b}$ and Table 1) by strengthening the production of raindrops at any snow mixing ratio and regardless of temperature, strongly influence the profile of the rain microphysics.

We decided to perform an additional simulation (called THOM-BKP) where the parameterization of the raindrop breakup is modified (details in section $2 \mathrm{~b}$ and in Table 1). As the modifications made by Brown et al. (2017) (similar to THOM-N25) are implemented by default in the Thompson scheme from the WRF version 3.8.1, the changes in the melting scheme are kept in THOM-BKP.

As in the idealized study of Morrison et al. (2012), Figs. S2f and S3 of the supplemental material show that modifying the efficiency of the raindrop breakup process influences the radar reflectivity fields. In THOM-BKP, the SR is similar to THOM-CTL and THOM-N25 in terms of reflectivity intensity but much shorter in time for few cross sections. Note that the simulated squall line often ends via a long period of light rain $(Z$ much smaller than $35 \mathrm{dBZ}$ ) compared to the observations. Therefore this period is not included in the SR in order to compare similar rain regimes. As in THOM-CTL and THOM$\mathrm{N} 25$, the model struggles to reproduce the TZ (i.e., its duration is significantly shorter than observed when it exists). The abnormally short trailing SR simulated at the SGP site (Fig. 2f) is a peculiarity of this location in THOM-BKP due to embedded convection at around 0800 UTC, which is not reproduced at other locations
(Fig. S3 of the supplemental material). Comparison of THOM-BKP with radar-retrieved $D_{m}$ (Fig. 4a) indicates that the model still produces values that are too small within the SR, despite the smaller bias in the reflectivity fields. The model still produces an important decrease of $N_{0}^{*}$ with decreasing height (Fig. 4b). Figure 5a also shows a strong vertical decrease of the rain mixing ratio $\left(q_{r}\right)$. This is probably due to the higher concentration of drops that amplifies the evaporation over the rain layer in THOM-BKP compared to in THOM-CTL (as will be shown in section 5). While the simulated $D_{m}$ and $N_{0}^{*}$ are improved thanks to the reduction of breakup in THOMBKP compared to THOM-N25, they remain worse than in THOM-CTL because of the excessive production of raindrops induced by the changes in THOM-N25 (i.e., the change in the melting scheme).

\section{b. Morrison scheme}

Figures 2c, 2e, 2g, 3, and 5b (as well as Figs. S4 and S5 of the supplemental material) show the results of the sensitivity study of the squall line to the parameterization of raindrop breakup using the Morrison scheme. As described in section $2 \mathrm{~b}$, the size threshold for breakup, $D_{\text {th }}$, used in the modified Verlinde and Cotton (1993) parameterization is varied between $105 \mu \mathrm{m}$ in MORR105 and $510 \mu \mathrm{m}$ in MORR-510, compared to $300 \mu \mathrm{m}$ in MORR-CTL. A similar sensitivity study was performed in Morrison et al. (2012).

Unlike the idealized squall line considered in Morrison et al. (2012), the radar reflectivity field is always overestimated (Fig. 2). The radar reflectivity fields show that in MORR-510 the life cycle of the squall line is modified (i.e., the CR can often be larger than in MORR-CTL, but the $\mathrm{TZ}$ is still smaller than in the observations). In MORR-105, the radar reflectivity is lower in CR than in MORR-CTL but remains above the observed values. Based on Fig. 5, we can note that the simulated liquid and ice contents are quite similar using the Morrison scheme (as in THOM simulations) except for the snow species above 8-km height and for the graupel species. While the simulated ice mixing ratio remains within the range of observations from 5 - to $10-\mathrm{km}$ height, the reflectivity is largely overestimated in the ice part of the SR (by more than $10 \mathrm{~dB}$ ). The differences in the reflectivity fields and the ice contents suggest that the reflectivity is overestimated either because snow particles are assumed too dense (Varble et al. 2014) or because too many large snow particles are present.

Regarding the rain microphysics, increasing $D_{\text {th }}$ to $510 \mu \mathrm{m}$ (in MORR-510) results in smaller $N_{0}^{*}$ and larger $D_{m}$ along the whole profile within the SR, which amplifies the discrepancies of these two DSD parameters relative to observations (Fig. 3). This strong vertical 
variation of $N_{0}^{*}$ and $D_{m}$ (decrease and increase toward the ground, respectively) suggests that the drop size sorting during the hydrometeors sedimentation is excessive (as in MORR-CTL). Setting $D_{\text {th }}$ to $105 \mu \mathrm{m}$ (in MORR-105) produces values of $D_{m}$ and $N_{0}^{*}$ that are quite comparable to observations all along the profile within the SR, implying that the breakup process is not efficient enough in MORR-CTL.

An additional sensitivity experiment is performed using the Morrison scheme in order to investigate the effects of the size sorting. This is done by setting the number-weighted mean fall speed equal to the massweighted mean fall speed [see Milbrandt and McTaggartCowan (2010) for more details]. Figure 3 shows the median vertical profiles of $D_{m}$ and $N_{0}^{*}$ obtained without size sorting and with the same $D_{\text {th }}$ values as in the previous experiment on breakup parameterization (see Table 1). The vertical variation of $D_{m}$ and $N_{0}^{*}$ for MORR-SS, MORR-510-SS, and MORR-105-SS simulations becomes smaller over the rain layer which is in better agreement with the observations. However, this experiment shifts the whole profiles of $D_{m}$ and $N_{0}^{*}$ further from the observations. In particular, in MORR-105SS the vertical evolutions of $D_{m}$ and $N_{0}^{*}$ differ from the other simulations. Because the vertical variation in MORR-105 is very weak, removing the size sorting leads to unrealistic vertical profiles of $D_{m}$ and $N_{0}^{*}$. Indeed, the vertical profiles in MORR-105-SS become opposite compared to the observations.

\section{Impact of the inaccuracy in the DSD representation on evaporation}

While the atmospheric relative humidity (RH) itself drives the intensity of the evaporation/condensation process, choices in the DSD representation can also have an impact on this process and hence on the precipitation intensity. In an attempt to quantify the impact of inaccuracies in the DSD profiles simulated in section 4 on the evaporation process, the evaporation rate is calculated in an empirical way using the mean retrieved RH (black line on Fig. 6a) from lidar observations (the methodology was described in Part I). Note that RH is about $60 \%$ near the surface and decreases with height up to $2-\mathrm{km}$ height and then slightly increases close to the melting level. The evaporation rate (ER) (in $\mathrm{g} \mathrm{kg}^{-1} \mathrm{~s}^{-1}$ ) at each level is defined as

$$
\mathrm{ER}=\left|\frac{2 \pi \rho_{w}}{\rho_{\text {air }}} \int_{0}^{D_{\max }} \frac{(S-1)}{F_{k}+F_{D}} D N(D) d D\right|,
$$

where $\rho_{\text {air }}$ and $\rho_{w}$ are, respectively, the density of air and water at the level considered and $S=\mathrm{RH} / 100$.
The terms $F_{k}$ and $F_{D}$ are related to heat conduction and vapor diffusion of air, respectively, and also include the ventilation coefficients (Pruppacher and Klett 1997). Next to the prevailing RH, Eq. (8) shows that the evaporation rate is mainly dependent on the concentration of the raindrops $N(D)$ and their sizes $D$. A larger raindrop concentration can evaporate a larger water mass while the evaporation process is slightly more efficient for larger raindrops.

Figures $6 \mathrm{~d}$ and $7 \mathrm{~d}$ present the mean vertical profile of the evaporation rate for the SR derived from observations and from each simulation described above using the mean retrieved RH profile (black line on Fig. 6a). The evaporation rate mirrors the slight vertical increase of $N_{0}^{*}$ with height, which is opposite to the vertical variation in $D_{m}$. Considering this analysis, it seems that the drop concentration is the essential parameter for a good estimation of the evaporation rate. Consequently, the radar retrievals of the DSDs should provide accurate estimates of the number concentration (Tridon et al. 2017a) and should not be restricted to $D_{m}$ [as done in, e.g., Giangrande et al. (2010); Matrosov (2017)]. Correspondingly, the validation of numerical simulations should also use the concentration parameter and not be limited to the mean volume diameter only [as in, e.g., Morrison et al. (2012); Brown et al. (2017)]. Moreover, as expected, the bias between evaporation rate calculated from both observations and simulations are consistent with the errors in the $D_{m}$ and $N_{0}^{*}$ profiles shown in section 4. Indeed, with the Morrison scheme, the smallest discrepancies for $D_{m}$ and $N_{0}^{*}$ found in MORR105 lead to a better quantification of the evaporation rate (Fig. 6d). The ER is underestimated by around $10 \%$ along the profile in MORR-105 whereas the underestimation in MORR-510 reaches $60 \%-65 \%$. The best estimation of the ER is obtained for THOM-CTL (underestimated by $\approx 5 \%-10 \%$ ), a direct consequence of the closeness of the simulations $D_{m}$ and $N_{0}^{*}$ to the observations in the Thompson scheme (Fig. 7d).

In a second approach, the ERs modeled by WRF (i.e., using modeled RH and modeled DSD parameters) from either scheme are compared to the observations. From MORR simulations (Fig. 6c), we can see that even if the ER modeled in MORR-105 is the closest to the observations, it is still underestimated by a factor 2 . For THOM simulations (Fig. 7c), the ER modeled in THOM-CTL is the furthest to the observations because DSD biases found in THOM-N25 and THOM-BKP are compensated by biases in the RH profile. Indeed, Figs. 6a,b and 7a,b show a comparative analysis between observations and simulation results for the mean $\mathrm{RH}$ and vertical motion in the SR (i.e., two parameters that have a great impact on the ER). The observed vertical 

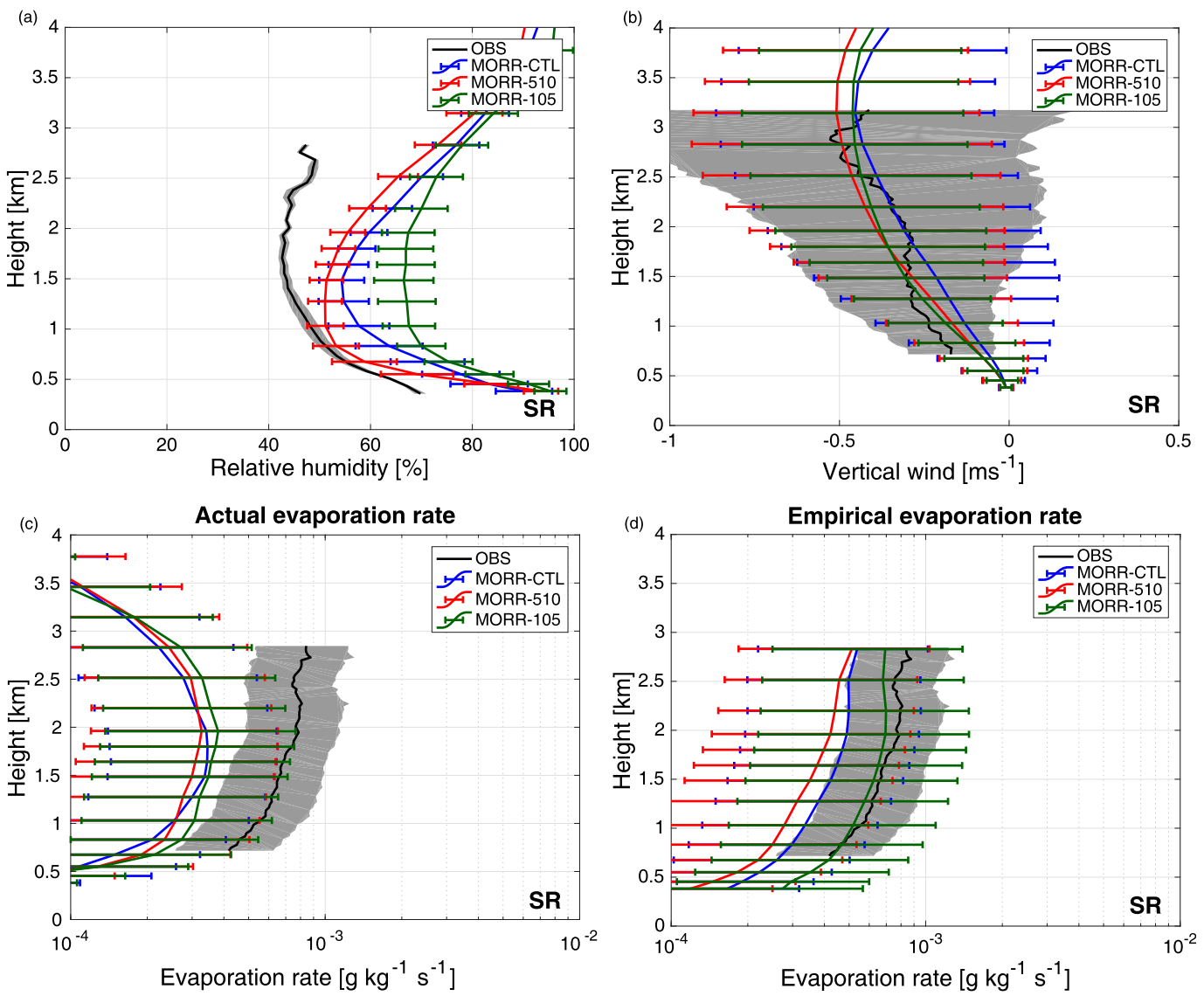

FIG. 6. Mean vertical profile in the SR for (a) the relative humidity, (b) the vertical wind, (c) the actual evaporation rate, and (d) an empirical evaporation rate from simulations. The empirical evaporation rates from simulations are computed thanks to Eq. (8), using the mean retrieved RH profile from lidar observations (see Part I) and the modeled DSD parameters obtained in MORR-CTL, MORR-510, and the MORR-105. The mean retrieved evaporation rate from observations is compared both to the (c) actual and (d) empirical simulated evaporation rate. The negative sign for the vertical wind indicates downdrafts. The averages are done using the different model timeheight sections defined in section 3 .

motion is obtained thanks to the multifrequency cloud radar Doppler spectra retrieval technique described in Part I. The magnitude of the mesoscale downdrafts that commonly occur in the SR of a squall line [as described, e.g., in Biggerstaff and Houze (1993)] are well reproduced within the rain layer whereas the RH is overestimated for all experiments. As expected, the higher the ER, the higher the atmospheric RH. The model's difficulty in reproducing the ER in the SR using either the Thompson scheme or the Morrison scheme could then affect the strength of the cold pool through latent cooling (Morrison et al. 2012).

\section{Summary and conclusions}

The representation of the rain microphysics has long been identified as a critical aspect for simulated squallline systems in mesoscale models such as WRF. To evaluate the ability of the microphysics parameterizations within WRF to reproduce the rain properties (i.e., the DSD temporal and vertical evolution), simulations obtained using the Thompson and the Morrison bulk microphysics schemes are compared to observations of the mean volume diameter $\left(D_{m}\right)$ and the concentration parameter $\left(N_{0}^{*}\right)$. These observations are derived from a recently developed retrieval technique based on multifrequency cloud radar Doppler spectra observations (Tridon et al. 2017a).

The observed and simulated radar reflectivity of the leading convective line and trailing stratiform region (SR) of the squall line under study are well simulated; however, the typical weak echo in the transition zone (TZ) (i.e., the period with light precipitation located after the convective line) is not. A statistical analysis of rain profiles in the squall-line system within the SR shows that both DSD parameters obtained with the 

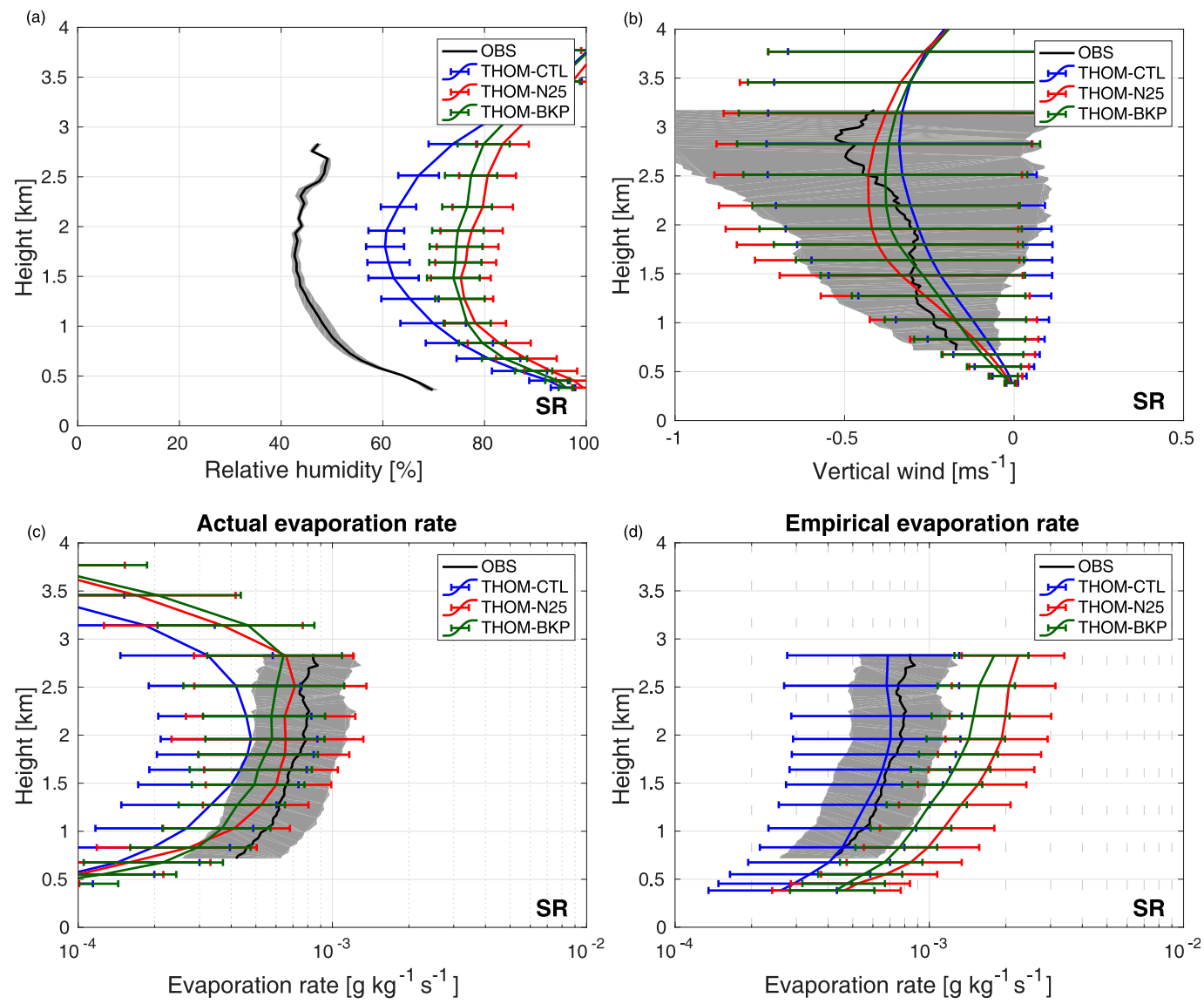

FIG. 7. As in Fig. 6, but for THOM-CTL, THOM-N25, and THOM-BKP simulations.

Thompson scheme are close to the observations whereas the results obtained with the Morrison scheme reveal a sharp increase (decrease) of $D_{m}\left(N_{0}^{*}\right)$ toward the ground that is not visible in the retrievals. The vertical variations of the DSD parameters suggest an issue in the current representation of the raindrop breakup and self-collection, or other effects that are dominating the vertical evolution, such as the evaporation or an excessive size sorting during sedimentation.

Comparisons with a basic retrieval of ice water content suggest that the observed discrepancies in rain do not originate from the ice phase, which is reasonably well reproduced by the model. This also suggests that the general overestimation of the ice reflectivity in the stratiform part of Morrison scheme simulations is due to either snow particles assumed too dense or too many large snow particles. Sensitivity studies are performed in order to further investigate the discrepancies in the DSD representation using both bulk microphysics schemes. To estimate the impact of the snow melting process on the DSD characteristics, a first sensitivity study is made on the representation of this process using the modifications described in Brown et al. (2017) (in WRF releases since version 3.8) for the Thompson scheme. Additional sensitivity studies are performed on the parameterization of the rain microphysics, and especially on the drop breakup formulation by varying the mean drop size threshold $\left(D_{\text {th }}\right)$ for breakup using the modified version of Verlinde and Cotton (1993) in both Thompson and Morrison schemes.

The representation of melting in the Thompson scheme has a strong influence on the properties of the rain microphysics. The changes made (detailed in Table 1) in the snow melting process lead to a further departure of the profile of DSD properties (i.e., $D_{m}$ and $N_{0}^{*}$ ) from observations (e.g., the number concentration parameter varied by an order of magnitude at the top of the rain layer in the SR). Additional changes in the breakup process improve the $D_{m}$ and $N_{0}^{*}$ profiles but they are still far from the observations. To avoid the divergence induced by the change in the parameterization of the melting process, a new representation of the ice phase microphysics in the Thompson scheme following the same approach as in Morrison and Milbrandt (2015) or additional changes in the melting process may help to better represent the DSD properties. Likewise, the 
graupel characteristics (e.g., density and fall velocity constants) can greatly influence the anvil region and then affect the amount of mass reaching the melting level (Adams-Selin et al. 2013).

In the Morrison scheme, the DSD characteristics are strongly influenced by the breakup process. A more efficient breakup tends to improve the ability of the model to reproduce the DSD in the SR. This result is consistent with the idealized study performed by Morrison et al. (2012) and the work of Gao et al. (2011) and could suggest to use the modified Verlinde and Cotton (1993) breakup parameterization with a size threshold $D_{\text {th }}$ equal to $105 \mu \mathrm{m}$ instead of $300 \mu \mathrm{m}$. Like other twomoment microphysics schemes, the Morrison results suffer from excessive size sorting and although we tested another sensitivity experiment designed to remove the size sorting, the results shifted further from the observations. Although our results on the need of a more efficient breakup process seem convincing, additional studies using a similar experimental setup on other precipitating systems need to be performed in order to check if this threshold diameter $D_{\text {th }}$ can be adopted to other rain regimes as well. Furthermore, more accurate retrievals are needed in order to characterize the CR and the ice phase.

We also investigate how the representation of the DSD properties influences the evaporation rate within the SR. This analysis shows that the discrepancies in $D_{m}$ and $N_{0}^{*}$ in the control simulations induce an underestimation of the evaporation rate by a factor of 2 . Moreover, the concentration parameter $N_{0}^{*}$ appears to be the essential parameter for quantitative estimates of evaporation rate, which suggests that observations should primarily aim at providing such parameter. Another comparison shows that, even if the vertical downdrafts common in the SR of a squall-line system is well reproduced within the rain layer, the evaporation rate simulated in WRF Model is underestimated, impacting the modeled relative humidity. Even though the cold pool is partly controlled by convective downdrafts, the model's inability in reproducing the evaporation rate could impact not only the rain rate at the ground but also the strength of the cold pool [as shown in previous work, e.g., in Morrison et al. (2012)]. Therefore, since the cold pool intensity is known as a critical factor in determining a squall-line structure and evolution (Rotunno et al. 1998; Weisman and Rotunno 2004), future work should analyze how the DSD differences impact the evolution of the squall line through latent cooling changes.

Even if the two-moment bulk microphysics schemes add realism to the simulation of sedimentation over a single-moment scheme (as used in Planche et al. 2015), Milbrandt and McTaggart-Cowan (2010) showed that they tend to lead to excessive drop size sorting, which can be greatly reduced by the use of three-moment schemes (e.g., Milbrandt and Yau 2005; Shipway and Hill 2012; Hill et al. 2015). As the size sorting impacts the vertical structure of the DSD properties, simulations with a three-moment bulk microphysics scheme must be performed in future works in order to clearly assess the effect of the drop breakup and self-collection parameterization. It could also be interesting to use a bin microphysics scheme, such as DESCAM (Flossmann and Wobrock 2010; Planche et al. 2010, 2014) or HUCM (Khain et al. 2004; Lynn and Khain 2007), in order to further study the rain microphysics processes by comparing the evolution of rain properties using bin and bulk microphysics schemes.

Acknowledgments. The lead author would like to thank Chief Editor Hugh Morrison, Alain Protat, and two other anonymous reviewers for their precise and constructive comments that have significantly contributed to the improvement of the article. This work was funded by the project "Evaluation de la Modélisation microphysique des Précipitations à l'aide d'Observations Radars Multifréquences (EMPORiuM)" and by the "WRF-DESCAM" project, both funded by the French CNRS-INSU LEFE-IMAGO programme. This research used the SPECTRE and ALICE High Performance Computing Facilities at the University of Leicester for radar retrieval techniques. The WRF calculations have been done on French computer facilities of the Institut du Développement des ressources en Informatique Scientifique (IDRIS) CNRS at Orsay, the Centre Informatique National de l'Enseignement Supérieur (CINES) at Montpellier under the project 940180 and the Centre Régional de Ressources Informatiques (CRRI) at Clermont-Ferrand. F. Tridon is funded by the AWARE project funded by the U.S. Department of Energy (DOE) within the Atmospheric System Research program (DESC0017967). Observational data were obtained from the U.S. DOE ARM Climate Research Facility www.archive.arm.gov.

\section{REFERENCES}

Adams-Selin, R. D., S. C. van den Heever, and R. H. Johnson, 2013: Impact of graupel parameterization schemes on idealized bow echo simulations. Mon. Wea. Rev., 141, 1241-1262, https://doi.org/10.1175/MWR-D-12-00064.1.

Atlas, D., and C. W. Ulbrich, 1977: Path- and area-integrated rainfall measurement by microwave attenuation in the $1-3 \mathrm{~cm}$ band. J. Appl. Meteor., 16,1322-1331, https://doi.org/10.1175/ 1520-0450(1977)016<1322:PAAIRM>2.0.CO;2.

, R. C. Srivastava, and R. S. Sekhon, 1973: Doppler radar characteristics of precipitation at vertical incidence. Rev. Geophys., 11, 1-35, https://doi.org/10.1029/RG011i001p00001. 
Barthes, L., and C. Mallet, 2013: Vertical evolution of raindrop size distribution: Impact on the shape of the DSD. Atmos. Res., 119, 13-22, https://doi.org/10.1016/j.atmosres.2011.07.011.

Biggerstaff, M. I., and R. A. Houze Jr., 1993: Kinematics and microphysics of the transition zone of the 10-11 June 1985 squall line. J. Atmos. Sci., 50, 3091-3110, https://doi.org/10.1175/ 1520-0469(1993)050<3091:KAMOTT >2.0.CO;2.

Blahak, U., 2007: RADAR_MIE_LM and RADAR_MIELIBCalculation of radar reflectivity from model output. Internal Rep., Institute for Meteorology and Climate Research, University of Karlsruhe, Karlsruhe, Germany, 150 pp.

Brown, B. R., M. M. Bell, and G. Thompson, 2017: Improvements to the snow melting process in a partially double moment microphysics parameterization. J. Adv. Model. Earth Syst., 9, 1150-1166, https://doi.org/10.1002/2016MS000892.

Bryan, G. H., and H. Morrison, 2012: Sensitivity of a simulated squall line to horizontal resolution and parameterization of microphysics. Mon. Wea. Rev., 140, 202-225, https://doi.org/ 10.1175/MWR-D-11-00046.1.

Evans, J. S., and C. A. Doswall, 2001: Examination of derecho environments using proximity soundings. Wea. Forecasting, 16, 329-342, https://doi.org/10.1175/1520-0434(2001) 016<0329:EODEUP $>2.0$.CO;2.

Fan, J., and Coauthors, 2017: Cloud-resolving model intercomparison of an MC3E squall line case: Part I-Convective updrafts. J. Geophys. Res. Atmos., 122, 9351-9378, https://doi.org/ 10.1002/2017JD026622.

Ferrier, B. S., 1994: A double-moment multiple-phase four-class bulk ice scheme. Part I: Description. J. Atmos. Sci., 51, 249-280, https:// doi.org/10.1175/1520-0469(1994)051<0249:ADMMPF>2.0.CO;2.

, W.-K. Tao, and J. Simpson, 1995: A double-moment multiple-phase four-class bulk ice scheme. Part II: Simulations of convective storms in different large-scale environments and comparisons with other bulk parameterizations. J. Atmos. Sci., 52, 1001-1033, https://doi.org/10.1175/1520-0469(1995) 052<1001:ADMMPF $>2.0 . \mathrm{CO} ; 2$.

Flossmann, A. I., and W. Wobrock, 2010: A review of our understanding of the aerosol-cloud interaction from the perspective of a bin resolved cloud scale modelling. Atmos. Res., 97, 478-497, https://doi.org/10.1016/j.atmosres.2010.05.008.

Fridlind, A. M., and Coauthors, 2017: Derivation of aerosol profiles for MC3E convection studies and use in simulations of the 20 May squall line case. Atmos. Chem. Phys., 17, 5947-5972, https://doi.org/10.5194/acp-17-5947-2017.

Gao, W., C.-H. Sui, T.-C. C. Wang, and W.-Y. Chang, 2011: An evaluation and improvement of microphysical parameterization from a two-moment cloud microphysics scheme and the Southwest Monsoon Experiment (SoWMEX)/Terrain-influenced Monsoon Rainfall Experiment (TiMREX) observations. J. Geophys. Res., 116, D19101, https://doi.org/10.1029/2011JD015718.

Giangrande, S. E., E. P. Luke, and P. Kollias, 2010: Automated retrievals of precipitation parameters using non-Rayleigh scattering at $95 \mathrm{GHz}$. J. Atmos. Oceanic Technol., 27, 14901503, https://doi.org/10.1175/2010JTECHA1343.1.

Hill, A. A., B. J. Shipway, and I. A. Boutle, 2015: How sensitive are aerosol-precipitation interactions to the warm rain representation? J. Adv. Model. Earth Syst., 7, 987-1004, https://doi.org/ 10.1002/2014MS000422.

Hogan, R. J., M. P. Mittermaier, and A. J. Illingworth, 2006: The retrieval of ice water content from radar reflectivity factor and temperature and its use in evaluating a mesoscale model. J. Appl. Meteor. Climatol., 45, 301-317, https://doi.org/ 10.1175/JAM2340.1.
Houze, R. A. J., 1977: Structure and dynamics of a tropical squall line system. Mon. Wea. Rev., 105, 1540-1567, https://doi.org/ 10.1175/1520-0493(1977)105<1540:SADOAT>2.0.CO;2.

Jensen, A. A., J. Y. Harrington, and H. Morrison, 2018: Microphysical characteristics of squall-line stratiform precipitation and transition zones simulated using an ice particle propertyevolving model. Mon. Wea. Rev., 146, 723-743, https://doi.org/ 10.1175/MWR-D-17-0215.1.

Khain, A. P., A. Pokrovsky, M. Pinsky, A. Seifert, and V. Phillips, 2004: Simulation of effects of atmospheric aerosols on deep turbulent convective clouds using a spectral microphysics mixed-phase cumulus cloud model. Part I: Model description and possible applications. J. Atmos. Sci., 61, 2963-2982, https:// doi.org/10.1175/JAS-3350.1.

Kumjian, M. R., and A. V. Ryzhkov, 2010: The impact of evaporation on polarimetric characteristics of rain: Theoretical model and practical implications. J. Appl. Meteor. Climatol., 49, 1247-1267, https://doi.org/10.1175/2010JAMC2243.1.

Liu, J. Y., and H. D. Orville, 1969: Numerical modeling of precipitation and cloud shallow effects on mountain-induced cumuli. J. Atmos. Sci., 26, 1283-1298, https://doi.org/10.1175/ 1520-0469(1969)026<1283:NMOPAC $>2.0 . C O ; 2$.

Lynn, B., and A. Khain, 2007: Utilization of spectral bin microphysics and bulk parameterization schemes to simulate the cloud structure and precipitation in a mesoscale rain event. J. Geophys. Res., 112, D22205, https://doi.org/10.1029/ 2007JD008475.

Mansell, E. R., 2010: On sedimentation and advection in multimoment bulk microphysics. J. Atmos. Sci., 67, 3084-3094, https://doi.org/10.1175/2010JAS3341.1.

Marshall, J. S., and W. M. Palmer, 1948: The distribution of raindrops with size.J. Meteor., 5, 165-1966, https://doi.org/10.1175/ 1520-0469(1948)005<0165:TDORWS >2.0.CO;2.

Matrosov, S. Y., 2017: Characteristic raindrop size retrievals from measurements of differences in vertical Doppler velocities at Ka- and W-band radar frequencies. J. Atmos. Oceanic Technol., 34, 65-71, https://doi.org/10.1175/JTECH-D-16-0181.1.

Matson, R. J., and A. W. Huggins, 1980: The direct measurement of the sizes, shapes, and kinematics of falling hailstones. J. Atmos. Sci., 37, 1107-1125, https://doi.org/10.1175/1520-0469(1980) 037<1107:TDMOTS $>2.0$. CO 2 .

Milbrandt, J. A., and R. McTaggart-Cowan, 2010: Sedimentationinduced errors in bulk microphysics schemes. J. Atmos. Sci., 67, 3931-3948, https://doi.org/10.1175/2010JAS3541.1.

__, and M. K. Yau, 2005: A multimoment bulk microphysics parameterization. Part I: Analysis of the role of the spectral shape parameter. J. Atmos. Sci., 62, 3051-3064, https://doi.org/ 10.1175/JAS3534.1.

Morrison, H., and J. Milbrandt, 2011: Comparison of two-moment bulk microphysics schemes in idealized supercell thunderstorm simulations. Mon. Wea. Rev., 139, 1103-1130, https:// doi.org/10.1175/2010MWR3433.1.

- , and,- 2015 : Parameterization of cloud microphysics based on the prediction of bulk ice particle properties. Part I: Scheme description and idealized tests. J. Atmos. Sci., 72, 287 311, https://doi.org/10.1175/JAS-D-14-0065.1.

— , G. Thompson, and V. Tatarskii, 2009: Impact of cloud microphysics on the development of trailing stratiform precipitation in a simulated squall line: Comparison of one- and two-moment schemes. Mon. Wea. Rev., 137, 991-1007, https:// doi.org/10.1175/2008MWR2556.1.

_ S. A. Tessendorf, K. Ikeda, and G. Thompson, 2012: Sensitivity of a simulated midlatitude squall line to parameteriza- 
tion of raindrop breakup. Mon. Wea. Rev., 140, 2437-2460, https://doi.org/10.1175/MWR-D-11-00283.1.

Nissan, H., and R. Toumi, 2013: Dynamic simulation of rainfall kinetic energy flux in a cloud resolving model. Geophys. Res. Lett., 40, 3331-3336, https://doi.org/10.1002/grl.50622.

Parker, M. D., and R. H. Johnson, 2000: Organizational modes of midlatitude mesoscale convective systems. Mon. Wea. Rev., 128, 3413-3436, https://doi.org/10.1175/1520-0493(2001) 129<3413:OMOMMC > 2.0.CO;2.

Planche, C., W. Wobrock, A. I. Flossmann, F. Tridon, J. V. Baelen, Y. Pointin, and M. Hagen, 2010: The influence of aerosol particle number and hygroscopicity on the evolution of convective cloud systems and their precipitation: A numerical study based on the COPS observations on 12 August 2007. Atmos. Res., 98, 40-56, https://doi.org/10.1016/ j.atmosres.2010.05.003.

,-- , and -2014 : The continuous melting process in a cloudscale model using a bin microphysics scheme. Quart. J. Roy. Meteor. Soc., 140, 1986-1996, https://doi.org/10.1002/qj.2265.

— J. H. Marsham, P. R. Field, K. S. Carslaw, A. A. Hill, G. W. Mann, and B. J. Shipway, 2015: Precipitation sensitivity to autoconversion rate in a numerical weather-prediction model. Quart. J. Roy. Meteor. Soc., 141, 2032-2044, https://doi.org/ 10.1002/qj.2497.

Pruppacher, H. R., and J. D. Klett, 1997: Microphysics of Clouds and Precipitation. Kluwer Academic, 954 pp.

Redelsperger, J.-L., and J.-P. Lafore, 1988: A three-dimensional simulation of a tropical squall line: Convective organization and thermodynamic vertical transport. J. Atmos. Sci., 45, 1334-1356, https://doi.org/10.1175/1520-0469(1988)045<1334: ATDSOA $>2.0 . \mathrm{CO} ; 2$

Rotunno, R., J. B. Klemp, and M. L. Weisman, 1998: A theory for strong, long-lived squall lines. J. Atmos. Sci., 45, 463-485, https://doi.org/10.1175/1520-0469(1988)045<0463:ATFSLL> 2.0.CO;2.

Shipway, B. J., and A. A. Hill, 2012: Diagnosis of systematic differences between multiple parametrizations of warm rain microphysics using a kinematic framework. Quart. J. Roy. Meteor. Soc., 138, 2196-2211, https://doi.org/10.1002/qj.1913.

Skamarock, W. C., and Coauthors, 2008: A description of the Advanced Research WRF version 3. NCAR Tech. Note NCAR/ TN-475+STR, 113 pp., https://doi.org/10.5065/D68S4MVH.

Straka, J. M., 2009: Cloud and Precipitation Microphysics: Principles and Parameterizations. Cambridge University Press, 392 pp.

Testud, J., S. Oury, R. A. Black, P. Amayenc, and X. K. Dou, 2001: The concept of "normalized" distribution to describe raindrop spectra: A tool for cloud physics and cloud remote sensing. J. Appl. Meteor., 40, 1118-1140, https://doi.org/10.1175/15200450(2001)040<1118:TCONDT>2.0.CO;2.

Thompson, G., R. M. Rasmussen, and K. Manning, 2004: Explicit forecasts of winter precipitation using an improved bulk microphysics scheme. Part I: Description and sensitivity analysis. Mon. Wea. Rev., 132, 519-554, https://doi.org/10.1175/15200493(2004)132<0519:EFOWPU>2.0.CO;2.

—, P. R. Field, R. M. Rasmussen, and W. D. Hall, 2008: Explicit forecasts of winter precipitation using an improved bulk microphysics scheme. Part II: Implementation of a new snow parameterization. Mon. Wea. Rev., 136, 5095-5115, https:// doi.org/10.1175/2008MWR2387.1.

Tridon, F., and A. Battaglia, 2015: Dual-frequency radar Doppler spectral retrieval of rain drop size distributions and entangled dynamics variables. J. Geophys. Res. Atmos., 120, 5585-5601, https://doi.org/10.1002/2014JD023023.
P. Kollias, E. Luke, and C. R. Williams, 2013: Signal postprocessing and reflectivity calibration of the Atmospheric Radiation Measurement program $915-\mathrm{MHz}$ wind profilers. J. Atmos. Oceanic Technol., 30, 1038-1054, https://doi.org/ 10.1175/JTECH-D-12-00146.1.

$\longrightarrow,-$, E. Luke, and P. Kollias, 2017a: Rain retrieval from dual-frequency radar Doppler spectra: Validation and potential for a midlatitude precipitating case study. Quart. J. Roy. Meteor. Soc., 143, 1363-1380, https://doi.org/10.1002/ qj.3010.

, -, and D. Watters, 2017b: Evaporation in action sensed by multiwavelenth Doppler radars. J. Geophys. Res. Atmos., 122, 9379-9390, https://doi.org/10.1002/2016JD025998.

, C. Planche, K. Mroz, S. Banson, A. Battaglia, J. V. Baelen, and W. Wobrock, 2019: On the realism of the rain microphysics representation of a squall line in the WRF Model. Part I: Evaluation with multifrequency cloud radar Doppler spectra observations. Mon. Wea. Rev., 147, 2787-2810, https://doi.org/10.1175/MWR-D-18-0018.1.

van Weverberg, K., A. M. Vogelmann, H. Morrison, and J. A. Milbrandt, 2012: Sensitivity of idealized squall-line simulations to the level of complexity used in two-moment bulk microphysics schemes. Mon. Wea. Rev., 140, 1884-1907, https://doi.org/10.1175/MWR-D-11-00120.1.

Varble, A., and Coauthors, 2014: Evaluation of cloud-resolving and limited area model intercomparison simulations using TWP-ICE observations: 2. Precipitation microphysics. J. Geophys. Res. Atmos., 119, 13 919-13 945, https://doi.org/ 10.1002/2013JD021372.

Verlinde, H., and W. R. Cotton, 1993: Fitting microphysical observations of nonsteady convective clouds to a numerical model: An application of the adjoint technique of data assimilation to a kinematic model. Mon. Wea. Rev., 121, 27762793, https://doi.org/10.1175/1520-0493(1993)121<2776: FMOONC $>2.0 . \mathrm{CO} ; 2$.

Verlinde, J., P. J. Flatau, and W. R. Cotton, 1990: Analytical solutions to the collection growth equation: Comparison with approximate methods and application to the cloud microphysics parameterization schemes. J. Atmos. Sci., 47, 2871-2880, https://doi.org/10.1175/1520-0469(1990)047<2871: ASTTCG $>2.0 . \mathrm{CO} ; 2$.

Wacker, U., and A. Seifert, 2001: Evolution of rain water profiles resulting from pure sedimentation: Spectral vs. parameterized description. Atmos. Res., 58, 19-39, https://doi.org/10.1016/ S0169-8095(01)00081-3.

Walko, R. L., W. R. Cotton, M. P. Meyers, and J. Y. Harrington, 1995: New RAMS cloud microphysics parameterization. Part I: The single-moment scheme. Atmos. Res., 38, 29-62, https:// doi.org/10.1016/0169-8095(94)00087-T.

Weisman, M. L., and R. Rotunno, 2004: "A theory for strong longlived squall lines" revisited. J. Atmos. Sci., 61, 361-382, https:// doi.org/10.1175/1520-0469(2004)061<0361:ATFSLS > 2.0. CO; 2 .

Wen, J., and Coauthors, 2017: Evolution of microphysical structure of a subtropical squall line observed by a polarimetric radar and a disdrometer during OPACC in Eastern China. J. Geophys. Res. Atmos., 122, 8033-8050, https://doi.org/ 10.1002/2016JD026346.

Zipser, E. J., 1977: Mesoscale and convective-scale downdrafts as distinct components of squall-line circulation. Mon. Wea. Rev., 105, 1568-1589, https://doi.org/10.1175/1520-0493(1977)105<1568: MACDAD $>2.0 . C O ; 2$. 